Research Article

\title{
An Exploration of Preschool Teachers' Perceptions of Physical Activity Integration in a Whole Child Pilot Curriculum
}

Alicia Stapp *, Madalyn Falkenheiner, Kenya Wolff

Department of Teacher Education, University of Mississippi, University, MS 38655, USA; E-Mails: acstapp@olemiss.edu; mmfalken@go.olemiss.edu; kewolff@olemiss.edu

* Correspondence: Alicia Stapp; E-Mail: acstapp@olemiss.edu

Academic Editor: Elaine Yee-Sing Wong

Special Issue: Physical Activity and Nutrition Intervention for Children

Recent Progress in Nutrition

2022, volume 2 , issue 1

doi:10.21926/rpn.2201001
Received: November 15, 2021

Accepted: January 07, 2022

Published: January 13, 2022

\begin{abstract}
It is recommended that children ages 3-5 receive 180 minutes of physical activity a day, with at least 60 minutes of moderate-to-vigorous physical activity. Despite these recommendations, a majority of preschoolers are not provided opportunities in the early childhood education setting to meet these daily recommendations through either structured or unstructured physical activity. Accordingly, the number of young children identified as overweight or obese over the past couple of decades has increased. Critical to addressing this epidemic is the role of physical activity in the early childhood classroom and its capacity to increase healthy development and lifelong habits for young children. Participants in this study consisted of 23 Pre-K 4 teachers from 5 different preschools across North Mississippi. A phenomenological approach was utilized to determine if the barriers to physical activity implementation in early childhood education classrooms were effectively addressed through the Growing Healthy Minds, Bodies, and Communities curriculum. This was completed by garnering teachers' perceptions of the curriculum through pre- and post-focus groups. Three themes emerged from the data regarding teachers' perceptions of the Growing Healthy Minds, Bodies, and Communities physical activity curriclum. Those themes are as follows: (a) teacher and student benefits of and engagement with physical activity in early childhood
\end{abstract}

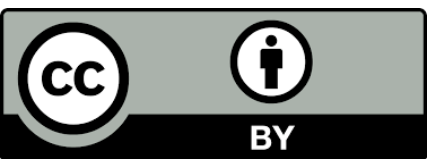

(C) 2022 by the author. This is an open access article distributed under the conditions of the Creative Commons by Attribution License, which permits unrestricted use, distribution, and reproduction in any medium or format, provided the original work is correctly cited. 
education; (b) shifting the mindset from "fitting it all in" to "making it work with modifications"; and (c) linking it to literacy. The opportunity for young children to participate in physical activity is a critical determinant of their overall health and development. While there has been an overall decrease in opportunities for preschool children to participate in both unstructured and structured physical activity, it is crucial to view physical activity as an essential and integrated component of the curriculum. When viewed through this lens, it provides a foundation that promotes lifelong healthy habits and development of children who become happy, healthy, and productive citizens in society.

\section{Keywords}

Early childhood; physical activity; teacher perceptions; curriculum intervention

\section{Introduction}

The next generation is entering a crisis as the global childhood trend toward obesity and unhealthy lifestyle behaviors is a growing concern [1]. Although the World Health Organization [2] recommends 180 minutes of physical activity (PA) per day, including 60 minutes of moderate-tovigorous physical activity (MVPA) for children ages 3-5, research reveals that children in child care settings across the United States spend only approximately 27 minutes of their day in MVPA [1]. A common misconception is that preschoolers are highly active and meet current recommendations with ease [3]. Conversely, research demonstrates that only $54 \%$ of preschoolers participate in at least 60 minutes of PA a day, ranging from low-to-vigorous [3, 4]. Additional research indicates that from 1990 to 2016, the number of children between 0-5 years considered overweight or obese increased from 32 million to 41 million globally [5]. This shift could result in a generation of children who may be the first in history to have a life expectancy shorter than that of their parents [6-8].

A critical behavior to addressing this epidemic is PA for young children [9], yet PA in the early childhood setting, particularly in the classroom, tends to be a point that is not consistently discussed or implemented [10]. However, PA is one of the most critical elements of a child's overall development [11]. During PA, both structured and unstructured, children have the potential to demonstrate mastery of skills and attitudes that may lead to more healthy behaviors later in life which, in turn, facilitates cognitive and social development $[4,10,11]$.

\section{Literature Review}

\subsection{Teaching the Whole Child}

Early childhood education (ECE) is a term that refers to programs and strategies of children from birth to age 8 wherein the foundations for cognitive, physical, and social-emotional development are formed. In recent years, social-emotional learning and school readiness have been at the forefront of ECE [1]. While social-emotional skills are certainly essential to children's overall development, Trybus [12] noted that there should be an emphasis on advocating for and teaching the whole child. Teaching the "whole child" means a whole child as one who is 
"intellectually active; physically, verbally, socially, and academically competent; empathetic, kind, caring and fair; creative and curious; disciplined, self-directed and goal oriented; free; a critical thinker; confident; cared for and valued ([12], p.7)."While most traditional play-based classrooms are integrative and promote whole child learning, some less play-based ECE settings tend to address the three domains of learning-physical, cognitive, and social-emotional-as separate entities [10, 11]. However, it is important to emphasize that these domains are intrinsically interwoven, such that the facilitation of one enhances the others [10,13]. Accordingly, carefully planned instruction in ECE that is inclusive of PA and social-emotional competence is both desirable and potentially of great benefit for nurturing children's development $[10,14]$.

\subsection{Importance of Physical Development for Young Children}

While all domains of development must be fostered in young children, it is important to emphasize that early childhood is a critical time for children to develop individual physical activity patterns [15]. Experts acknowledge that children should be exposed to ample amounts of PA through both structured and unstructured play inclusive of active outdoor and free play as well as through educational experiences that increase PA capacity [16]. However, contrary to what is known about the benefits of both outdoor play and PA for young children, access to such opportunities have diminished due to such factors as fears of accidents, increased use of technology, and time and space [17-20].

While including PA in the curriculum and increasing outdoor play time may be beneficial, early childhood educators must possess essential knowledge of physical development in order to understand how increases or decreases in PA affect young children's development. Research shows that increased PA routines in ECE help develop children's motor competence [4, 11, 21]. Motor competence is a broad term that encompasses fundamental movement skill abilities, including; locomotor, object control, stability factors, and motor coordination [4]. Previously it has been hypothesized that children with better motor competence participate in higher levels of PA, which assists with developing higher actual and perceived motor competence [4]. Zeng [11] completed a systematic review examining the effects of PA on preschool children's motor skill outcomes. Results indicated that eight of ten studies reported significant improvements in motor development (e.g., fundamental motor skills and motor abilities) following activity-based interventions [11].

In contrast to the aforementioned benefits, there are consequences when motor skills are not addressed at a young age $[10,14]$. Although children do develop motor skills at different rates, a lack of PA may result in incomplete physiological development [7]. Physical activity in early childhood stimulates growth by supporting normal bone and muscle development. If children are not afforded ample opportunities to practice fundamental motor skills, then it is likely they will have limited opportunities for successful engagement in PA later in life [22]. Thus, these skills are critical to developing habits that will extend and translate into lifelong healthy PA habits.

\subsection{Structured and Unstructured Physical Activity for Young Children}

In addition to the importance of physical development for young children, it is also crucial to delineate between opportunities for structured and unstructured PA in early childhood settings. Structured PA differs from unstructured PA in that it is carefully planned and directed with 
intention by an adult or teacher [5]. Unstructured PA, however, is child-directed or self-selected [10]. In this type of movement, the student explores and learns by themselves. While young children may have a multitude of unstructured PA opportunities during the school day, it is important to note that young children should experience both structured and unstructured PA [23].

Demonstrating the importance of both types of PA, Palmer [3] examined preschoolers' PA engagement during two different PA opportunities: outdoor free play and a structured movement lesson. The study revealed that structured movement time afforded children an opportunity to engage in more PA than outdoor time alone [3]. Additional research has demonstrated that the type and quality of PA relates more to motor skill development than simply movement quantity and intensity $[4,24]$. These findings support the notion that preschools should provide children with daily structured PA opportunities inclusive of formalized instruction in addition to regularly scheduled outdoor free play $[25,26]$. While both forms of PA and play are important (structured and unstructured) they are even more powerful when used and implemented together [27]. Thus, preschools should consider multiple opportunities for gross motor activity that includes outdoor recess and play, and a planned movement program inclusive of physically active lessons and movement breaks during classroom instruction time $[3,13,28]$.

\subsection{Types of Physical Activity and Interventions in Early Childhood Education}

According to the Centers for Disease Control and Prevention (CDC), there are three categories of PA which should be addressed in order to meet the daily PA recommendations within a comprehensive school PA plan. These interventions include aerobic activity, muscle-strengthening activities, and bone-strengthening activities. These interventions should be developmentally appropriate and included as part of children's daily 60 minutes or more of PA at least 3 days out of the week [29]. Activities can include but are not limited to walking, running, and climbing.

Young children approach learning in a unique way that must be accommodated if they are to experience positive outcomes, as they still learn primarily through play, relying heavily on imitation and experimentation [30]. Coupled with this knowledge, Kelly [31] found that preschoolers' physical abilities changed after moderate interventions. Two different preschool programs were examined with 47 children ( 27 females and 20 males), ages 3-5 years old. Children in one preschool received physical education instruction (50 minutes, twice a week for 12 weeks) in six basic skills: underhand ball roll, two-handed catch, in-step kick, overhand throw, horizontal jump, and sidearm strike. Children in the control preschool received daily recess but no physical education [30]. Outcomes revealed that the intervention improved in all areas of the intended skills, whereas the control group showed no change in physical skills.

\subsection{Teachers' Perceptions and Barriers to Physical Activity in Early Childhood Education}

As evidenced above, the need for PA in the ECE classroom is critical, not only for children's physical health but as a gateway to all other domains. Physical literacy educates individuals about their physicality, which not only pertains to 'being physical', but encapsulates an embodied understanding of how to be physical by interacting with varied and challenging environments [32]. Developing physical literacy is not a simple task, but is necessary in the early childhood classroom [33]. So, why do some schools not implement structured PA into their curriculum and/or routines 
during the day? A majority of the literature indicates that lack of time, space, and resources are a substantial obstacle in realizing greater participation in structured physical activities at child care centers and preschools, which substantiates the reasons why opportunities for children to be physically active are decreasing [14, 28, 34]. According to Veldaman [35], when teachers are intentional with their practices there is a profound influence on children's learning and health. Thus, the intention of educators in their daily practice is critical to changing the physical, cognitive, and social and emotional health trajectories of the children they teach [35].

Additional barriers to utilizing daily PA in the early childhood classroom have been noted as a lack of training, access to natural settings, and safety concerns [7, 27, 36]. Similar reasons have also been reported by primary school teachers (e.g., lack of time, necessary teaching skills and knowledge, social and financial school support, teachers' self-efficacy, and attitudes toward physical activity) [37-39]. These barriers are important to note as teachers' own perceptions about PA are determinants of how they promote and/or utilize PA in their classrooms [40]. A possible antidote to these barriers is providing early childhood educators with the tools and knowledge necessary to understand why and how PA can be implemented within their curriculum [1, 7]. Other means to supporting an increase in young children's PA opportunities is to include the use of flexible seating, readjusting the preschool environment (i.e., relocating facilities around the space), movement breaks, physically active lessons (i.e., PA integrated during learning), and movement transitions between activities [7].

An example of a program that includes the aforementioned is Children's Health Activity Motor Program (CHAMP), which consists of a dance-based warm-up activity, a variety of motor skills stations, and physical activity games [3]. Another program entitled 'Jump Start' was designed to provide multiple opportunities to integrate PA into the daily routine of the childcare center [34]. These programs in addition to training for teachers may provide the support needed to increase both capacity and early childhood educators' perceptions of the critical need for young children to be exposed to both structured and unstructured PA throughout each day.

\subsection{A Curriculum Framework for Integrating Physical Activity into the Early Childhood Setting}

Although there are a multitude of barriers to PA implementation, programs that address such perceived barriers to implementation may be critical to changing the landscape of PA in the early childhood classroom. Taking this into consideration, the pilot program examined in this study, Growing Healthy Minds, Bodies, and Communities (GHMBC), aimed to address the deficiencies of program development and implementation found within the literature through strategic curriculum development and training.

Social-emotional development underpins the GHMBC program, while nutrition and gardening, diversity, community, and PA were layered into the 8 units taught over 8 months, consisting of 32 standards-based lessons (1 per week). Each lesson included one or more of the following early childhood standards: mathematics, science, social studies, and/or English language arts. In particular, this paper will solely examine teachers' perceptions of the weekly yoga videos that aligned with the GHMBC units (2 videos per unit) and the 2 PA units within the GHMBC curriculum, unit 5 (Exploring our Environment Through Movement) and unit 8 (Having a Ball Rolling into Summer) (see Appendix A). 
Prior to implementation of $\mathrm{GHMBC}$, teachers were provided virtual training on the importance of PA for the ECE classroom, basic knowledge on developmentally appropriate PA, fundamental movement skills for young children, and verbal cues for teaching motor skills that were to be taught during the structured PA lessons. Because this pilot occurred during the COVID-19 pandemic (2020-2021), we could only provide training virtually. Therefore, teachers were required to view 60-90 minute online module videos developed by the GHMBC research team prior to each PA unit and successfully complete a 10 question assessment on the material before teaching the PA units.

The units were created to be scaffolded and aligned with the state-mandated curriculum, Open the World of Learning (OWL). Thus, the GHMBC PA lessons align with the same themes and academic content taught within the preschools' curriculum. This was done intentionally to alleviate any additional work for the teachers and aimed to mitigate the barrier of time. Additionally, all tangible resources were provided for teachers in a curriculum box and all digital resources were placed on the GHMBC website for ease of access. The focus of structured PA within the lessons moved from basic fundamental movement skills in unit 5 (stability, locomotor, manipulative) to utilizing manipulative skills in tandem with gross motor skills in games and creative movement in unit 8. The intention of this movement progression was to increase children's capacity of fundamental movement skills, both gross and fine motor, in structured and developmentally appropriate ways. In addition to the lessons, supplemental yoga videos were also created by the GHMBC team. For each unit, 2 yoga videos were provided that aligned with both the content and vocabulary taught during each unit to reinforce the skills and concepts taught. By addressing both the need for training, curriculum resources, and providing ample structured PA opportunities in these units, the GHMBC research team aimed to address the perceived barriers found within the literature to implementation of PA in the ECE setting as well as support feasible ways to begin incorporating PA into the daily classroom.

\section{Methods}

To determine if the barriers to PA implementation in ECE classrooms were effectively addressed through the GHMBC curriculum framework, this study investigated teachers' perceptions of the PA units within the GHMBC pilot program through a phenomenological approach. This method enabled the researchers to study the teachers' perceptions as they manifested within their lived experiences throughout the pilot study [41]. By examining how others subjectively live an experience, new ideas and appreciations can be developed in order to better inform or even re-imagine how those experiences are understood [42].

Participants within this study included 23 Pre-K4 teachers from 5 preschools across North Mississippi. A convenience sample was utilized as 3 of the schools had previously piloted the GHMBC program during the 2019-2020 school year. The two additional schools were selected due to the geographical location of the schools that were pre-determined from a grant the researchers received to pilot GHMBC during 2020-2021. Demographics of the teachers were $74 \%$ White and 26\% African American. Prior to implementation of the study, approval from the university's Institutional Review Board was approved in addition to a signed Memorandum of Understanding from either the preschool's principal/director or the school district's superintendent. Additionally, 
teacher consent and parental consent for their child's data collection was obtained prior to the study.

\subsection{Data Collection}

To capture teachers' experiences and perceptions of the PA units during the GHMBC pilot program, focus groups were administered both pre- and post-hoc. Due to the nature of the COVID-19 pandemic, pre-focus groups were held via Zoom during July 2020 and post-focus groups were conducted face-to-face during May 2021. Focus groups for 3 of the schools were held in an open area community pavilion that was centrally located to the schools and consisted of 4-5 teachers ( 3 focus groups total) and the additional 2 schools focus groups ( 5 teachers) were conducted within one of the school's cafeteria for convenience of the teachers. The researchers conducted the focus groups and each focus group had a researcher who audio recorded and hand wrote notes. Pre-focus group questions asked teachers to share in general their attitudes and perceptions about GHMBC, while post-focus group questions focused on teachers' experiences with all components and implementation of GHMBC and areas for improvement (see Appendix B). All participants were encouraged to share differing viewpoints through the use of techniques such as "the pause and the probe" ([43], p.99). Wait time was also utilized (3-5 seconds) to encourage participants who were not as vocal to respond throughout the focus groups.

\subsection{Data Analysis}

Pre-focus groups were recorded on Zoom and live audio transcripts were created via Zoom. Since all of the post-focus groups were conducted face-to-face they were recorded on a recording device (e.g., Ipad, phone, laptop) and transcribed through the Otter.ai application. Two of the researchers independently coded for themes in the data in order to identify commonalities between the following constructs of the focus group questions: (a) interest and engagement with the curriculum, (b) experiences and perception of PA in the ECE classroom, (c) perceived and actual barriers to including PA in the ECE classroom, and (d) experiences with implementation of the GHMBC PA units. After the commonalities were determined, the themes were categorized from these constructs into micro-themes and were then evaluated for potential high-level interconnectedness in order to aggregate them into final high-order themes [44]. This process was iterative and inclusive of moving between both the raw data and micro-themes a multitude of times in order to accurately capture teachers' perceptions. Member checking was used via debriefing and discussion of data interpretation to ensure validity and reliability [45]. Transcripts were reviewed multiple times until the point of saturation was met [46].

\section{Results}

Outcomes revealed three themes that emerged from the pre- and post-focus groups regarding teachers' perceptions of PA in ECE throughout the GHMBC pilot curriculum. The following themes are described in detail below: (a) teacher and student benefits of and engagement with PA in ECE; (b) shifting the mindset from "fitting it all in" to "making it work with modifications"; and (c) linking it to literacy. 


\subsection{Teacher and Student Benefits of and Engagement with PA in ECE}

During both the pre- and post-focus groups many participants shared that they understood and knew the benefits of PA in the early childhood classroom and were able to experience some of the benefits in their own classrooms as a result of participating in the GHMBC pilot curriculum. While some participants had prior experience utilizing physical activity in their classrooms or were part of the previous year's GHMBC pilot (2019-2020), other participants who had not previously piloted or had used very little PA in their classrooms revealed that they had high hopes for what the GHMBC pilot curriculum would be able to provide in terms of the benefits and engagement with PA. One teacher noted the following:

I guess I am kind of hoping it will help them develop lifelong skills that they can take with them, but you know it's good for them to know how to make healthy choices, to exercise daily, and to take care of themselves. And, then I need to take care of myself more too, so, maybe I can get a little of that out of piloting the Growing Healthy Minds, Bodies, and Communities curriculum.

For teachers who had utilized PA in the classroom before, a majority noted the use of videos rather than intentional structured integration of PA into the curriculum. Several teachers mentioned that they incorporated videos such as "Cosmic Kids Yoga," while others noted that "Move to Learn" was their go-to choice for getting students moving and engaged throughout the day. One platform that was mentioned by several of the teachers was "Go Noodle" due to students' engagement with it according to the following teacher's statement:

We did Go Noodle every day after lunch and if I didn't want to do it that day or whatever, they would stop me and say, "no we haven't done our dance." They remembered every day, so we had to do it every day. They were always excited about it and always ready to move!

While some teachers recognized the benefits of PA solely for their students, one teacher who had previously piloted the GHMBC curriculum the previous year mentioned that it was more a matter of recognizing how the PA, specifically yoga, had been beneficial for both her and the students in her classroom.

I've done it personally at my gym. There are a couple of options you can choose from and me and my sister always choose yoga. It's our top choice because it's so relaxing and calming, and I find at the end of the day that's where I can go and calm down and not be like a mile a minute because that's what our day is full of. I think the kids need that too. We always try to do yoga towards the end of centers, like right before transitions so they can kind of calm down and then we go into lunch and have a nap, so it gets them ready to fuel their body and then rest their body, which we found is really good. So I know personally for me if I am thinking okay this is helping, it's calming me down, then you know it's going to help them too because they need that as well. Another teacher also noted during the pre-focus group how the use of breath during the yoga videos that she had participated in during the GHMBC curriculum the previous year had helped her throughout the school day.

I could just feel myself last year with the yoga teacher's voice at the end where we did those breathing things. It was like I'm not even here with 18 four year olds. It was like I was in my own zen world because it really does kind of center you and relax you and it was helpful for me too, even though I'm not very flexible, but I liked the yoga.

After participating in the GHMBC curriculum with 2 PA units a majority of the teachers recognized the deficiency of PA in their state mandated curriculum and therefore a need for it to 
be integrated more often. One teacher suggested that PA should be "sprinkled in" more often "because OWL [state mandated curriculum] doesn't really offer a lot during the year for PA." This was reinforced by another teacher who mentioned the following:

I'll say I think OWL lacks gross motor activities. It's a lot of literacy and math. So it was beneficial to have these physical activity units because up until then, we haven't really had any intention, like learning how to jump or like, do all that and it was eye opening. Because for some students I was like, that'd be easy for them. But some of them struggle like when they were doing the sensory pathway during $G H M B C$ we saw a lot of friends struggle, which was very interesting to me, but it clued us in that we need to focus on this [motor skills] more.

Another teacher was surprised at how much engagement and joy the children experienced while participating in one of the PA videos that was aligned with the PA lesson in the PA jungle unit as noted below:

... and the jungle ones were good. Of course, they love the jungle animals, but I felt like the movement really made those lessons more exciting for them. So, the more excited they were, the easier it was to teach it and to go through it. And it was also fun seeing their faces. You were like, wow, they all really liked it!

An unexpected benefit of the PA units was that teachers mentioned how the PA was beneficial beyond its intentional use within the classroom and how it enabled students to engage with the PA skills and concepts more than just one time. One example was in regard to the Jungle Jump lesson where the children learned to complete a vertical jump with a guided video that provided motor movement cues for performing a vertical jump effectively.

Since they have learned the vertical jump they have not stopped. Because it's different when you're just jumping naturally, and then to teach them, where you are bringing in those parts of the body and how to do it. Once they get it, they want to keep doing it! So it was good to connect a name [vertical jump] to what you commonly do, and then to show them a different way, or a better way to do something you naturally can do. They were excited about it and did it a lot at the playground. Because it was something new, they wanted to do it over and over again and watch the video.

Another extension of the PA unit was with the sensory pathway which was utilized to emulate things found in the desert alongside movements that were associated with those items (e.g., mountains where children marched up the images of mountains). One teacher shared how the sensory pathway was beneficial with more than just PA for a few of her students.

I have three children that have occupational therapy and needs that we try to catch up with before they get overwhelmed. And, so we have a student worker that goes and takes those students one at a time to the sensory pathway and lets them burn off that energy and get that sensory input on before they hit their breaking point. It's been really helpful for that.

\subsection{Shifting the Mindset from "Fitting it All in" to "Making it Work with Modifications"}

Although the participants recognized the many benefits of, and engagement with intentionally incorporating structured PA units into their curriculum, they also expressed their concern with being able to "fit it all in." Since the GHMBC curriculum was supplemental to the state mandated curriculum, many teachers perceived that there would be a barrier of time and being able to fit it all in would be challenging. During the pre-focus groups one teacher mentioned, "I think that is a 
fear of every teacher, being able to fit everything in and to do a good job." Another teacher went even further in depth with her worry regarding the challenge of managing time:

I think that every teacher's concern every year is fitting it in. It never gets easier. Just trying to make sure that we get everything in and spend the most time where needed on certain things so we are not, you know, wasting time here and there, but I feel like time management is something that teachers struggle with every year.

With the state mandated curriculum being fairly new (2-3 years) for all of the teachers, as well as standards-based grading at one school where the pilot was implemented, additional concerns were expressed about the compounding mandates that were already placed on teachers during the pre-focus groups as revealed below.

Last year was our first year to do the OWL curriculum and so then when we had this too, it was just all a little overwhelming. Because you are trying to fit it all in and the state has all these guidelines, and so I just think you're constantly watching your time and we honestly, I'll speak honestly, we loved the program Growing Healthy Minds, Bodies, and Communities, but we were also glad to take something off of our plate, and it was not anything negative about the program. It was just, we had so much to do. I think that's a constant struggle with any teacher is just trying to fit it all in and then the more you do, of course the harder it is trying to fit it all in, especially when it's all good stuff.

In relation to standards-based grading and the concern with fitting in the GHMBC curriculum, another teacher mentioned the following:

Mine is always just in time and making sure we get everything that we need to get in, especially with OWL and standards-based grading and you know you just want to make sure you're covering everything and then when you do things you want to make sure you're doing it well. I don't like to have a bunch of stuff and not do it well. If I do something I want to make sure I'm doing it the way it has to be done so I'm just making sure it's done correctly.

While most of the teachers had previously taught Pre-K, one teacher expressed her concern in the context of time and being a new teacher to Pre- $K$ when asked about her fears and/or concerns about piloting GHMBC.

My concerns are especially being new to Pre-K this year and making sure that I cover

everything that I am supposed to cover. You know, so as far as the OWL curriculum, and then adding in this additional information for the kids too, and doing it justice is what I'm most concerned about this year.

Although the perceived barrier of being able to fit everything emerged during the pre-focus groups, a shift in mindset was revealed from the data that materialized during the post-focus groups. Many teachers expressed how they were able to make the PA units in the GHMBC curriculum work for their classroom by modifying the time and/or day they taught it and by modifying materials. One teacher noted that she was able to make yoga 3 times a week feasible by utilizing a specific day as noted below:

When we did it, I chose to do my lessons on Friday, because that's when I had an open time. But I knew I needed to do it earlier in the week so that we could continue to do the yoga that goes with that lesson. So that's one thing I changed and put our physical activity lesson toward the beginning of the week, so we could follow up with yoga and make sure we were doing it 3 times a week.

While one teacher was able to modify the day of the week she taught the lesson to accommodate integration of yoga 3 times a week, another teacher mentioned that she could 
"easily divide them into two lessons." The teacher noted that she "might do part of the lesson on Thursday and the second part on Friday." This modification enabled her to split the time throughout the week in order to incorporate the PA lessons into the week. Another point that emerged in the data was the modification of lesson materials. One teacher spoke in regard to the sensory pathway that was utilized in one of the PA units (see Figure 1).

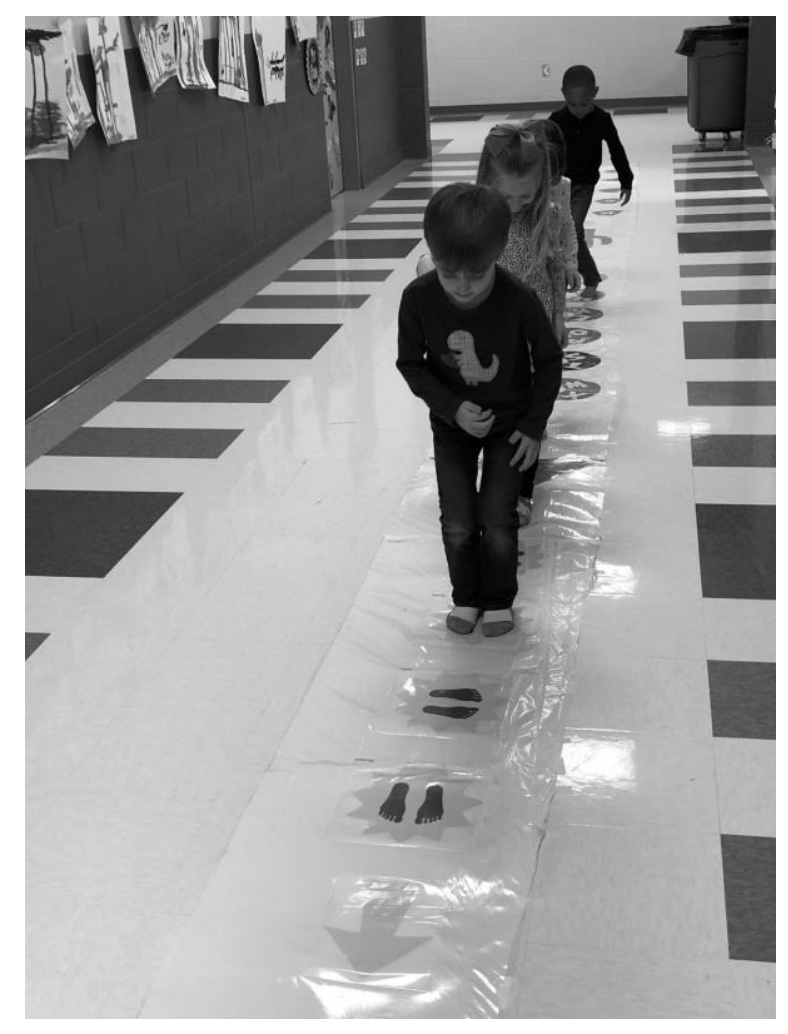

Figure 1 Students using the modified sensory pathway.

The big sensory pathway was amazing. And they did love it. And we have pulled it out on rainy days before because we were not able to put it on the floor. And so we put it on bulletin board paper, and then we laminated it. And so on rainy days, we just kind of pull it out and let the kids take their shoes off and explore the pathway.

Additional modifications and uses of the use of the sensory pathway were elicited in the following statements from teachers:

The first time we used it was not when we were teaching the pathway lesson, it was just for a rainy day for recess. And so we needed something that they could do. And my kids were tired of wondering, like, can we do something else? And so one of the other pre-k teachers said hey, let's bring up the sensory pathway, so we did. And they kept saying, Can we do it again? Can we do it? And mine are still asking for it. Like, if it rains, they're like, can we do that thing? They don't know what it's called but they're like, you know, that thing we read on and we walk on? They have just really enjoyed it.

One teacher even mentioned that she allowed her students to explore the sensory pathway to come up with their own ideas.

So we have some that want to crawl on the pathways like with their hands and knees on the footprint or like they want to jump. And then put them down almost like a burpee type thing. Like 
kind of roll on it. So I had some that needed that type of movement. And especially when it's not all 16 of them out there. There's kind of a little more leeway to let them do that when it's 16 you know..... then you're like, okay, come on, bring it back down. But when it's just two or three out there, it's really nice to see what they come up with.

\subsection{Linking it to Literacy}

In addition to the PA that was incorporated into the GHMBC pilot curriculum explored within this paper, the GHMBC team also chose to include books and literacy skills into the curriculum. Therefore, almost each PA lesson either had a book that corresponded with it and was provided or a suggested book was noted in the lesson. For example, in the "Balance Like a Jungle Animal" lesson, the $A B C$ Yoga book was utilized to encourage children to not only identify the first letter of each animal in the book but to also work on balance and coordination through yoga poses provided for each animal in the book. Because of this link to literacy, teachers revealed both their appreciation toward it and the specific books they thought were most beneficial as they piloted the lessons. One teacher even mentioned that it became part of her routine and an effective way to link learning at home.

I really liked every lesson that had a book that was associated with the lesson. I love literacy, I love finding books. It's like my jam. So any book, any lesson that had a book and kind of sat through it, because we always tried to do our lesson right after recess. And any other day, right after recess, I tried to refocus by reading a story. So having that be part of our routine just kind of made it seamless. And then the parents also like to hear about the books too!

The books also seemed to link in with the following teacher's routine as well.

...there were a lot of really great books, reading to the kids, and we were able to ask questions about them. And I felt like the kids really got engaged in quite a few of the different stories that we read. So, I always thought that was good. Because too many times now, we do a read aloud on the promethium so that I can pull kids, so for me to be able to read some more stories to them, that helps make sure all kids are provided the opportunity for a read aloud. So I thought those were good.

Teachers also appreciated the fact that the books provided were developmentally appropriate for both the age and content for the children as noted below. One teacher stated, "There were several books during the pilot and I thought the books were really helpful. I thought they were really on their level. And they could understand them. They were also very age appropriate." One book in particular - The Cactus Hotel - used during the third PA lesson, "Trekking Through The Desert" was mentioned as a book that was "able to hold their attention." One teacher noted, "I saw the students doing their cactus breathing during the story. They were really interested in it and were able to tell me whether they'd like to be a cactus or not." Not only were the books age appropriate, but teachers also expanded on the importance of how they extended the link to the book beyond just the lesson it was intended for. One book in particular that was integrated into a PA lesson, the $A B C$ yoga book, was repeatedly mentioned by the teachers as a go to book and one that was utilized many times and engaged both students and teachers.

....and the book that we got, ABC Yoga, the children loved that one. And they just asked me just one child as soon as she would teach the whole class how to get the book and they loved it. And I liked the books that came along like she said because now we're building our library with them. 
Another teacher also chimed in:

...the $A B C$ yoga book, I have put that in my music and movement center. So, they could read that and practice their yoga moves when they go to the center. There are several other books we've pulled out again too!

It was also mentioned that the books helped to balance the lessons and that the PA lessons

with the books were simple and short enough to follow.

I think that the book brought in a balance to the lesson. The ABC yoga book was great. The physical activity lessons were simple, which was very helpful. Because sometimes we don't have time. So, the simplicity of those lessons and the books were great to have as a supplement.

One teacher even mentioned how much she liked doing the $A B C$ yoga book with her students.

I always did the yoga videos with my students. And there was that book. There was a yoga book, the alphabet book. And I did every pose with them, and they loved having me do it with them as we would read through that book.

\section{Discussion}

Findings from this study revealed three main themes: (a) teacher and student benefits of, and engagement with PA in ECE; (b) shifting the mindset from "fitting it all in" to "making it work with modifications"; and (c) linking it to literacy. Grounded in these results are elements of support that the GHMBC pilot curriculum framework aimed to provide - integrated curriculum, PA training, and resources. This framework was developed and implemented with intentionality in order to work toward overcoming the perceived barriers that teachers experienced with structured PA during the GHMBC curriculum. Ultimately, our goal was to elicit takeaways from the pilot that can be applied toward and help us improve future implementation of the GHMBC curriculum.

A majority of the PA incorporated by the teachers, as noted throughout the pre-focus groups was in the form of PA videos and not intentionally integrated into the daily lessons in a structured manner. While one of the barriers of incorporating structured PA into the ECE classroom mentioned in the literature is time [28, 34], the GHMBC curriculum aimed to break down the barrier of time by intentionally incorporating structured PA into the lessons through an integrative approach to the curriculum. Most teachers do recognize the need for and benefits of PA for young children [14, 47]; however, it was not until many of them experienced it during the pilot that they realized that there are multiple layered benefits of incorporating PA into the curriculum. These benefits included the children's ability to self-regulate following PA opportunities, the teacher's ability to recognize a difference in their well-being (i.e., calmer, focused, energized), recognizing a deficiency in their own curriculum, and beginning to intertwine and extend PA into additional facets of the school day. This exposure to additional structured PA in the classroom is critical to overcoming the barrier and stigma that incorporating PA in the classroom brings with it as well as providing ample PA opprotunities for children.

In alignment with the literature, outcomes of this study also revealed that the more teachers experience the benefits of PA in the classroom for their students the more motivated they are to implement it in the future [48]. Specific to this study, a strategically designed PA curriculum that aligns with what the teachers are already expected to teach might have also encouraged teachers to extend the learned PA skills in the classroom as noted in the results. While this extension is 
promising it is also important to note that the training provided for teachers also provided a building block for teachers' awareness of the benefits PA provides for children. Although teachers may not have ample background knowledge on how to develop motor skill competence, as they are not trained physical education teachers, they were still able to verbally articulate and recognize some of the areas of skill deficiency in their students after implementing some of the structured PA lessons in GHMBC that included motor skill performance. In congruence with the literature, this could be a result of participating in the online module training and provides justification that training for ECE on PA may be a facilitator of PA in the classroom [7] and is essential to promotion of PA in the ECE classroom.

Another factor that facilitated engagement with the GHMBC curriculum and was interwoven through all of the teacher feedback was resources. During the pre-focus group teachers seemed to hone in on the barrier of time. However, due to the resources provided with the GHMBC curriculum, teachers were afforded opportunities to view the PA GHMBC units as a positive entity in their classroom through the facilitation of resources and materials. In congruence with the literature, resources are one of the largest facilitators to PA [49]. A few of the GHMBC resources mentioned by the teachers included weekly yoga videos, motor skill videos with cues, a sensory pathway mat, and children's books related to PA. Because teachers already noted that they utilized PA videos in the pre-focus groups they may have been naturally inclined to find it easy to incorporate the yoga videos. Additionally, research on the benefits of yoga for teachers aligns with the benefits that teachers shared with us regarding how they felt after participating in the yoga videos with the children (i.e., relaxed, calm, focused) $[50,51]$. Teachers were also able to utilize the videos and the sensory pathway embedded in the PA units a multitude of times and even extend ways to use the motor skill videos. Lastly, children's books were also a facilitator to the PA lessons. Because literacy and read alouds are conducted most days in the ECE classroom this may have helped to foster positive engagement with the PA lessons.

While there were many positive outcomes of this study, it is not without limitations. One limitation of this study is that all of the resources provided for the pilot were grant funded and therefore sustainability and continued buy-in heavily relies on school district and even state level adoption of the curriculum. Teachers who piloted the curriculum were also engaged with it and willing to engage with the supplemental curriculum. Thus, it was not a mandated curriculum and could be different if it was provided from an autocratic approach.

Results of the study are promising. However, it may be beneficial for future research and implementation of GHMBC to focus on providing additional resources, such as PA videos, as a way to continue to continue to engage teachers and improve PA outcomes for children. Additionally, piloting with additional schools in different geographical regions across the state of Mississippi would be helpful in developing a program that is inclusive of meeting a variety of schools needs. Lastly, assessing not only teachers' perceptions of the PA, but also garnering students' perceptions and also quantifying PA changes longitudinally throughout future iterations of the GHMBC curriculum might also provide further evidence for the critical need to include structured PA in the ECE classroom. 


\subsection{Conclusion}

Opportunities for PA are a critical determinant of young children's overall health and development. When implemented at a young age, PA also carries with it the ability to create lifelong healthy habits. However, the lack of structured PA integrated into the ECE curriculum is readily apparent, as well as teachers' knowledge and willingness to focus on ways to incorporate elements of structured PA into the ECE classroom. Nonetheless, with a strategically developed curriculum that focuses on the barriers and facilitators of PA in the ECE classroom it might be feasible to slowly transform the engrained stigma of employing PA in the ECE classroom from a separate entity of the curriculum to an essential and integrated component. Ultimately, providing a foundation that promotes the development of children who become happy, healthy, and productive citizens with the capacity to prosper socially, emotionally, cognitively, and physically in society.

\section{Acknowledgments}

This research was supported by a W.K. Kellogg Foundation grant.

\section{Additional Materials}

The following additional materials are uploaded at the page of this paper.

1. Appendix A.

2. Appendix B.

\section{Author Contributions}

Dr. Alicia Stapp was responsible for conceptualizing the present study, writing, editing, and revising the curriculum examined within the manuscript, and conducting data collection and data analysis. Dr. Stapp also wrote the methods, results, discussion, and conclusion sections of the manuscript, and edited and revised all sections of the manuscript. Ms. Madalyn Falkenheiner was responsible for writing the abstract, introduction, and literature review within this manuscript, editing and revising all sections of the manuscript, and formatting the manuscript. Dr. Kenya Wolff was responsible for conceptualizing the study and conducting data collection and data analysis. Dr. Wolff also edited all sections of the manuscript.

\section{Funding}

The work completed within this manuscript was supported by the W.K. Kellogg Foundation.

\section{Competing Interests}

The authors have declared that no competing interests exist.

\section{References}

1. Lu C, Montague B. Move to learn, learn to move: Prioritizing physical activity in early childhood education programming. Early Child Educ J. 2016; 44: 409-417. 
2. World Health Organization. Homepage [Internet]. Genève: World Health Organization; 2021 [cited 2021 October 28th]. Available from: https://www.who.int/.

3. Palmer KK, Matsuyama AL, Robinson LE. Impact of structured movement time on preschoolers' physical activity engagement. Early Child Educ J. 2017; 45: 201-206.

4. Barnett LM, Salmon J, Hesketh KD. More active pre-school children have better motor competence at school starting age: An observational cohort study. BMC Public Health. 2016; 16: 1068.

5. Dankiw KA, Tsiros MD, Baldock KL, Kumar S. The impacts of unstructured nature play on health in early childhood development: A systematic review. PloS ONE. 2020; 15: e0229006.

6. Cunningham SA, Kramer MR, Narayan KM. Incidence of childhood obesity in the United States. N Engl J Med. 2014; 370: 403-411.

7. Ellis YG, Cliff DP, Okely AD. Childcare educators' perceptions of and solutions to reducing sitting time in young children: A qualitative study. Early Child Educ J. 2018; 46: 377-385.

8. Patrick $H$, Hennessy $E$, McSpadden $K$, Oh A. Parenting styles and practices in children's obesogenic behaviors: Scientific gaps and future research directions. Child Obes. 2013; 9: S73S86.

9. Wyszyńska J, Ring-Dimitriou S, Thivel D, Weghuber D, Hadjipanayis A, Grossman Z, et al. Physical activity in the prevention of childhood obesity: The position of the European childhood obesity group and the European academy of pediatrics. Front Pediatr. 2020; 8: 662.

10. Stork S, Sanders SW. Physical education in early childhood. Elem Sch J. 2008; 108: 197-206.

11. Zeng N, Ayyub M, Sun H, Wen X, Xiang P, Gao Z. Effects of physical activity on motor skills and cognitive development in early childhood: A systematic review. BioMed Res Int. 2017; 2017: 2760716.

12. Trybus M. Advocating for the whole child: An interview with Dr. Nancy Gibson. Delta Kappa Gamma Bull. 2015; 82: 6-9.

13. Phajane $\mathrm{MH}$. Play as a medium for learning: Overwhelming challenges for early childhood teachers. Gend Behav. 2019; 17: 13962-13969.

14. Mavilidi MF, Rigoutsos S, Venetsanou F. Training early childhood educators to promote children's physical activity. Early Child Educ J. 2021. Doi: 10.1007/s10643-021-01191-4.

15. Bento G, Dias G. The importance of outdoor play for young children's healthy development. Porto Biomed J. 2017; 2: 157-160.

16. Mårtensson $F$, Boldemann $C$, Söderström $M$, Blennow $M$, Englund JE, Grahn P. Outdoor environmental assessment of attention promoting settings for preschool children. Health Place. 2009; 15: 1149-1157.

17. Brussoni M, Olsen LL, Pike I, Sleet DA. Risky play and children's safety: Balancing priorities for optimal child development. Int J Environ Res Public Health. 2012; 9: 3134-3148.

18. Tremblay MS, Esliger DW, Tremblay A, Colley R. Incidental movement, lifestyle-embedded activity and sleep: New frontiers in physical activity assessment. Can J Public Health. 2007; 98 : S208-S217.

19. Tremblay MS, Gray C, Babcock S, Barnes J, Bradstreet CC, Carr D, et al. Position statement on active outdoor play. Int J Environ Res Public Health. 2015; 12: 6475-6505.

20. Ross $A$, Wood $L$, Searle $M$. The indirect influence of child play on the association between parent perceptions of the neighborhood environment and sense of community. Health Place. 2020; 65: 102422. 
21. Mampane RM, Omidire MF, Ayob S, Sefotho MM. Using structured movement educational activities to teach mathematics and language concepts to preschoolers. South African J Child Educ. 2018; 8: a513.

22. Loprinzi PD, Cardinal BJ, Loprinzi KL, Lee $\mathrm{H}$. Benefits and environmental determinants of physical activity in children and adolescents. Obes Facts. 2012; 5: 597-610.

23. Kemple KM, Oh J, Kenney E, Smith-Bonahue T. The power of outdoor play and play in natural environments. Child Educ. 2016; 92: 446-454.

24. Logan SW, Robinson LE, Wilson AE, Lucas WA. Getting the fundamentals of movement: A meta-analysis of the effectiveness of motor skill interventions in children. Child Care Health Dev. 2012; 38: 305-315.

25. McArdle F, Grieshaber S, Sumsion J. Play meets early childhood teacher education. Aust Educ Res. 2019; 46: 155-175.

26. Zosh JN, Hopkins EJ, Jensen H, Liu C, Neale D, Hirsh-Pasek K, et al. Learning through play: A review of the evidence. Billund: LEGO Fonden; 2017.

27. Ernst J, Tornabene L. Preservice early childhood educators' perceptions of outdoor settings as learning environments. Environ Educ Res. 2012; 18: 643-664.

28. Brian A, Pennell A, Sacko R, Schenkelburg M. Preschool teachers' preparedness for knowing, enabling, and meeting the active start guidelines for physical activity. J Mot Learn Dev. 2018; 6: 333-344.

29. Centers for Disease Control and Prevention. How much physical activity do children need [Internet]? Atlanta: Centers for Disease Control and Prevention; 2021 [cited 2021 October 28th]. Available from: https://www.cdc.gov/physicalactivity/basics/children/index.htm.

30. Stork S, Sanders SW. You say potato, I say potäto: Problems associated with the lack of shared meaning in instruction and learning. Quest. 2000; 52: 60-78.

31. Kelly LE, Dagger J, Walkley J. The effects of an assessment-based physical education program on motor skill development in preschool children. Educ Treat Children. 1989; 12: 152-164.

32. Veigel M. Pre-school teachers, parents and their co-operation in supporting of the development of 4-7 years children 's physical activity. Proceedings of the SGEM 2014 International Multidisciplinary Scientific Conferences on Social Sciences and Arts; 2014 September 2nd-7th; Albena, Bulgaria. Sofia: Stef92 Technology.

33. Okely AD, Stanley RM, Jones RA, Cliff DP, Trost SG, Berthelsen D, et al. 'Jump start' childcarebased intervention to promote physical activity in pre-schoolers: Six-month findings from a cluster randomised trial. Int J Behav Nutr Phys Act. 2020; 17: 6.

34. Sum RK, Ha AS, Cheng CF, Chung PK, Yiu KT, Kuo CC, et al. Construction and validation of a perceived physical literacy instrument for physical education teachers. PLoS ONE. 2016; 11: e0155610.

35. Veldman SL, Stanley RM, Okely AD, Jones RA. The association between staff intention and preschoolers' physical activity in early childhood education and care services. Early Child Dev Care. 2020; 190: 2032-2040.

36. Coleman B, Dyment JE. Factors that limit and enable preschool-aged children's physical activity on child care centre playgrounds. J Early Child Res. 2013; 11: 203-221.

37. Naylor PJ, Nettlefold L, Race D, Hoy C, Ashe MC, Higgins JW, et al. Implementation of school based physical activity interventions: A systematic review. Prev Med. 2015; 72: 95-115. 
38. Webster CA, Buchan H, Perreault M, Doan R, Doutis P, Weaver RG. An exploratory study of elementary classroom teachers' physical activity promotion from a social learning perspective. J Teach Phys Educ. 2015; 34: 474-495.

39. Webster CA, Zarrett N, Cook BS, Egan C, Nesbitt D, Weaver RG. Movement integration in elementary classrooms: Teacher perceptions and implications for program planning. Eval Program Plann. 2017; 61: 134-143.

40. Morgan PJ, Hansen V. Physical education in primary schools: Classroom teachers' perceptions of benefits and outcomes. Health Educ J. 2008; 67: 196-207.

41. Creswell JW, Poth CN. Qualitative inquiry \& research design: Choosing among five approaches. 3rd ed. Thousand Oaks: SAGE Publication Inc.; 2018.

42. Laverty SM. Hermeneutic phenomenology and phenomenology: A comparison of historical and methodological considerations. Int J Qual Methods. 2003; 2: 21-35.

43. Krueger RA. Focus groups: A practical guide for applied research. Thousand Oaks: Sage publications; 2014.

44. Patton MQ. Qualitative evaluation and research methods. 2nd ed. Thousand Oaks: SAGE Publications; 1990.

45. Lincoln YS, Guba EG. Naturalistic inquiry. Thousand Oaks: Sage publications; 1985.

46. Strauss A, Corbin J. Basics of qualitative research techniques. Thousand Oaks: Sage publications; 1998.

47. Campbell AL, Lassiter JW. Teacher perceptions of facilitators and barriers to implementing classroom physical activity breaks. J Educ Res. 2020; 113: 108-119.

48. Brown KM, Elliott SJ. It's not as easy as just saying 20 minutes a day': Exploring teacher and principal experiences implementing a provincial physical activity policy. Univers J Public Health. 2015; 3: 71-83.

49. Weatherson KA, McKay R, Gainforth HL, Jung ME. Barriers and facilitators to the implementation of a school-based physical activity policy in Canada: Application of the theoretical domains framework. BMC Public Health. 2017; 17: 835.

50. Telles S, Sharma SK, Gupta RK, Pal DK, Gandharva K, Balkrishna A. The impact of yoga on teachers' self-rated emotions. BMC Res Notes. 2019; 12: 680.

51. Wolff K, Stapp A. Investigating early childhood teachers' perceptions of a preschool yoga program. SAGE Open. 2019; 9. Doi: 10.1177/2158244018821758. 


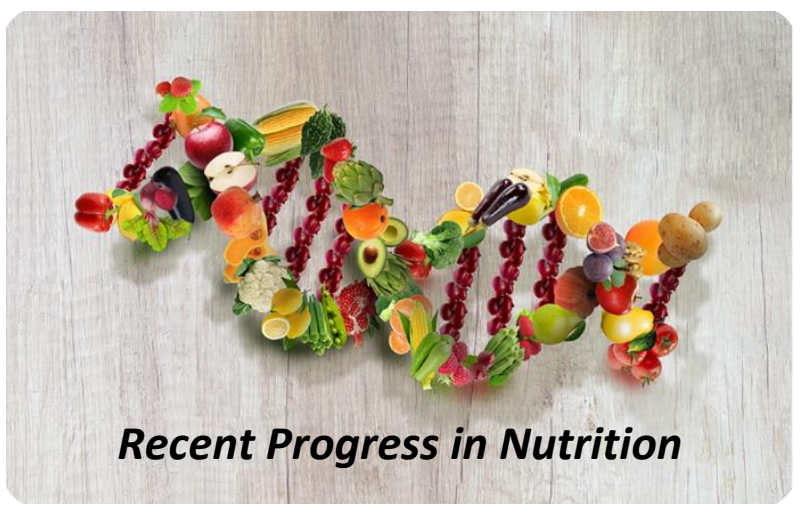

Enjoy Recent Progress in Nutrition by:

1. Submitting a manuscript

2. Joining in volunteer reviewer bank

3. Joining Editorial Board

4. Guest editing a special issue

For more details, please visit:

http://www.lidsen.com/journals/rpn 